\title{
'||||||||||||||||||||||||||||||||||||||||||||||||||||||||||||||||||||.
}

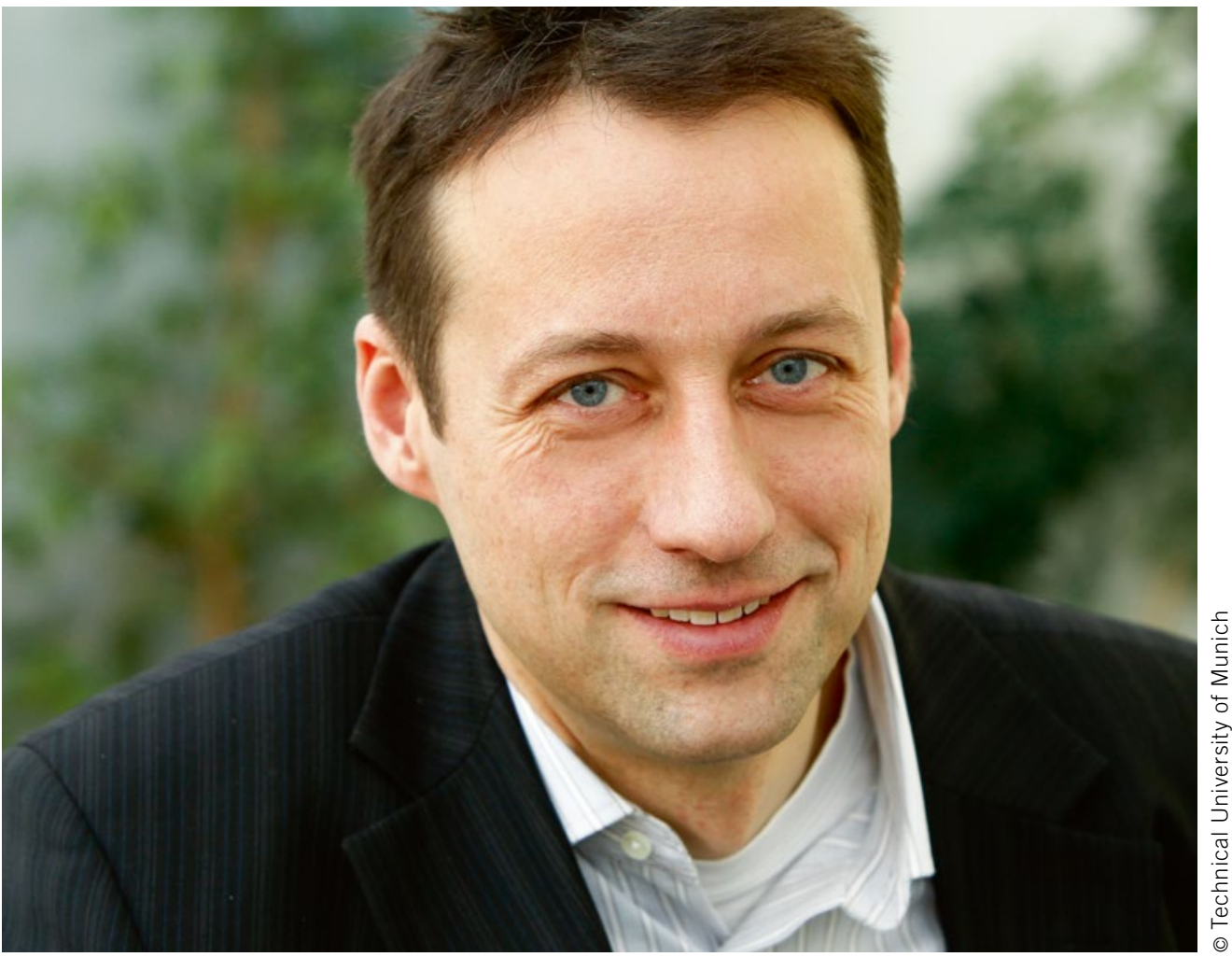

Prof. Dr.-Ing. Markus Lienkamp Institute of Automotive Technology, Technical University of Munich

\section{Money Scores Goals}

At universities, the situation is the same as in the world of football. If you have plenty of money, you can buy the latest equipment, appoint top-class professors and, as a result, offer high-quality research and teaching.

The Technical University of Munich is undoubtedly one of the best-equipped universities in Germany and has performed very well in national and international rankings over recent decades. However, our basic funding per student is only one third of that of the Swiss Federal Institute of Technology in Zurich and one eighth of that of the Massachusetts Institute of Technology in the USA. The financial support for the entire excellence initiative for all German universities over a period of five years is the same as Stanford's annual budget. In these circumstances, how can we expect to be competitive in the Champions League?

In the past, we have been successful because our professors have attracted large amounts of funding from industry to supplement the inadequate basic financing provided by the German federal states. This has allowed them to hire additional employees and research assistants who have played a decisive role in the field of research in particular. The research topics were chosen by the faculties and enhanced their expertise. The superbly educated engineers who achieved their PhDs are now sitting on the boards of OEMs and automotive suppliers.

Over the past few years, I and many of my colleagues have noticed that the mood has been changing in more and more large companies. A careful analysis of the benefits shows that in-house postgraduate students are more cost-effective. The company does not have to pay any overheads or the additional charges levied by universities for industrial PhD students. In addition, the students can focus solely on their research and the company can choose the research topic. The benefits are clear to the students and the businesses alike and apparently there are always enough fellow colleagues available to support the students. No one involved seems to be aware that this represents a huge loss to the universities. Either that or they are simply shrugging it off.

This is why we and some of those affected have written an open letter on the subject entitled "Industrial PhDs - the rules of good scientific practice”. This letter was published in mid February by the German Association of University Professors and Lecturers in the hope of encouraging businesses and the other organisations involved to give some thought to the issue. I will be very pleased if this prompts more of our colleagues to come around to our way of thinking. 